DOI: 10.12731/2658-6649-2019-11-5-2-90-94

УДК 616.995.122-08

\title{
ИЗМЕНЕНИЯ ИММУНОЛОГИЧЕСКИХ ПОКАЗАТЕЛЕЙ У БОЛЬНЫХ ХРОНИЧЕСКИМ ОПИСТОРХОЗОМ С КЛИНИКОЙ ПОРАЖЕНИЯ ГЕПАТОБИЛИАРНОЙ СИСТЕМЫ
}

Москаленко О.Л., Филимонова Л.А., Яскевич Р.А.

У больных хроническим описторхозом с клиникой поражения органов гепатобилиарной системы выявлены существенные изменения иммунологических показателей клеточного и гуморального звена иммунитета с увеличением циттотоксических лимфоцитов, снижении ИРИ и фагоцитарной активности клеток крови, в сравнении с паџиентами, у которых хронический описторхоз протекал бессимптомно.

Ключевые слова: хронический описторхоз; иммунологическая реактивность; гепатобилиарная система.

\section{CHANGES OF IMMUNOLOGICAL INDICES IN PATIENTS WITH CHRONIC OPISTHORCHIASIS WITH THE CLINIC OF LESIONS OF THE HEPATOBILIARY SYSTEM}

\section{Moskalenko O.L., Filimonova L.A., Yaskevich R.A.}

Patients with chronic opisthorchiasis with the clinic and lesions of the organs of the hepatobiliary system revealed significant changes in immunological parameters of cellular and humoral immunity with increase of cytotoxic lymphocytes, the reduction of IRI and phagocytic activity of blood cells, in comparison with the patients with chronic opisthorchiasis is asymptomatic

Keywords: chronic opisthorchiasis; immunological reactivity; hepatobiliary system.

При хроническом описторхозе длительное присутствие паразита нарушает функционирование органов гепатобилиарной системы и всего организма в целом [1]. Хроническая стадия заболевания вначале приводит к дисбалансу в иммунной системе, а затем к стойкому иммунодефициту [3]. 
Механизмом защиты от гельминтов при описторхозе является высокая продукция Ig Е и высокая эозинофилия крови, как проявление антипаразитарного иммунитета. В хроническую стадию описторхоза уровень Ig Е и эозинофилов снижается. Высокая метаболическая активность зрелых описторхисов, не только поддерживает длительное воспаление в местах обитания, но и формируют системный иммунный ответ [2].

Цель: Оценка иммунного статуса в зависимости от функционирования гепатобилиарной системы, в ответ на длительное присутствие паразита при хроническом описторхозе, по результатам иммунологических и клинических показателей.

\section{Материалы и методы исследования}

Обследовано 58 больных хроническим описторхозом. Из них 37 (63,6\%) пациентов с описторхозом и нарушениями со стороны гепатобилиарной системы, 21 пациент с описторхозом без изменений со стороны гепатобилиарной системы и 20 здоровых добровольцев, составившие контрольную группу.

Для подтверждения диагноза описторхоза использовались: иммуноферментный анализ, копроовоскопия и дуоденальное зондирование. Для оценки иммунного статуса проводили подсчет основных субпопуляций Т-лимфоцитов с помощью моноклональных антител на проточном цитометре. Концентрацию сывороточных иммуноглобулинов определяли методом ИФА. Уровень общего IgЕ определялся иммуноферментным методом люминолзависимой хемилюминесценции (ХЛ).

\section{Результаты и обсуждение}

Среди обследованных больных с описторхозом изменения в иммунной системе характеризовались напряжением гуморального звена: увеличением Ig G $(17,4$ г/л) и Ig E (119,1 ME). Отмечались изменениями Т-клеточного звена иммунитета и снижение фагоцитарной активности клеток крови. Наблюдался дисбаланс основных субпопуляций Т-клеточного звена иммунитета: уменьшение Т-хелперов, увеличении Т-цитотоксических лимфоцитов и снижении ИРИ среди лиц с клиническими проявлениями поражения гепатобилиарной системы, подтвержденные биохимическими показателями крови и поджелудочной железы. У больных с клиническими проявлениями поражения гепатобилиарной системы фоновая активность полинуклеаров оказалась выше, в то время как ответ на стимуляцию был ниже, что по-видимому может свидетельствовать о снижении функционального резерва клеток фагоцитарного звена. Среди больных хрониче- 
ским описторхозом в I группе ИХЛ был равен 4,63+ 0,26 (у.е.), а у лиц II группы 9,9+0,54 (p<0,01). По данным ЛЗХЛ снижение фагоцитарной активности клеток крови является следствием снижения иммунологической реактивности организма что приводит к несостоятельности иммунного ответа и может свидетельствовать о длительном течении инфекционного процесса и развитии вторичного иммунодефицита $[4,5]$. Первостепенное значение в процессе формирования противопаразитарного иммунитета имеет IgE. При гельминтозах развитие патологического процесса сопровождается образованием циркулирующих иммунных комплексов (ЦИК), содержащих IgE. Привлекая в очаг эозинофилы, влияющие на функцию Т- и В-лимфоцитов, макрофагов ЦИК формируют патологический симптомокомплекс, при этом в крови увеличивается содержание IgE, коррелирующее с тяжестью патологического процесса.

\section{Заключение}

У больных хроническим описторхозом с клиникой поражения органов гепатобилиарной системы выявлены существенные изменения иммунологических показателей клеточного и гуморального звена иммунитета с увеличением цитотоксических лимфоцитов и снижении ИРИ. У пацинтов с симптомами поражения гепатобилиарной области и поджелудочной железы отмечается снижение фагоцитарной, в результате есостоятельности иммунного ответа, в сравнении с пациентами, у которых хронический описторхоз протекал бессимптомно.

\section{Список литературы}

1. Бакштановская И.В., Степанова К.Б., Кальгина Г.А., Степанова Т.Ф. Взаимосвязи биохимических и иммунологических показателей у больных хроническим описторхозом // Мед. паразитол.и паразит. болезни. 2018. № 17. С. 13-19.

2. Бычков В.Г., Крылов Г.Г., Сабиров А.Х. Динамика клеточных преобразований в печени при экспериментальном описторхозе // Мед. паразитол.и паразит. болезни. 2008. № 3. С. 9-12.

3. Цуканов В.В., Филимонова Л.А., Борисенко Н.А. Клинико-иммуннологические особенности хронического описторхоза // Российский журнал гастроэнтерологии, гепатологии, колопроктологии. 2003. Т. 13. № 1. С. 52.

4. Филимонова Л.А., Борисенко Н.А. Описторхоз, клинические проявления // Сибирское медицинское обозрение. 2006. № 2 (39). С. 8-12.

5. Смирнова О.В., Титова Н.М., Каспаров Э.В., Елманова Н.Г. Хемилюминесцентная активность нейтрофильных гранулоцитов в прогрессировании 
механической желтухи в зависимости от уровня билирубина и генеза желтухи // Медицинская иммунология. 2016. Т. 18. № 3. С. 269-278.

\section{References}

1. Bakshtanovskaya I.V., Stepanova K.B., Kal'gina G.A., Stepanova T.F. Vzaimosvyazi biohimicheskih i immunologicheskih pokazatelej u bol'nyh hronicheskim opistorhozom [Interrelations of biochemical and immunological parameters in patients with chronic opisthorchiasis]. Med. parazitol.i parazit. Bolezni [Med. parasitol. and parasite]. 2018. № 17. S. 13-19.

2. Bychkov V.G., Krylov G.G., Sabirov A.H. Dinamika kletochnyh preobrazovanij $\mathrm{v}$ pecheni pri eksperimental'nom opistorhoze [Dynamics of cellular transformations in the liver in experimental opisthorchiasis]. Med. parazitol.i parazit. Bolezni [Med. parasitol. and parasite. diseases]. 2008. № 3. S. 9-12.

3. Cukanov V.V., Filimonova L.A., Borisenko N.A. Kliniko-immunnologicheskie osobennosti hronicheskogo opistorhoza [Clinical and immunological features of chronic opisthorchiasis]. Rossijskij zhurnal gastroenterologii, gepatologii, koloproktologii [Russian Journal of Gastroenterology, Hepatology, Coloproctology]. 2003. T. 13. № 1. S. 52.

4. Filimonova L.A., Borisenko N.A. Opistorhoz, klinicheskie proyavleniya [Opisthorchiasis, clinical manifestations]. Sibirskoe medicinskoe obozrenie [Siberian Medical Review]. 2006. № 2 (39). S. 8-12.

5. Smirnova O.V., Titova N.M., Kasparov E.V., Elmanova N.G. Hemilyuminescentnaya aktivnost' nejtrofil'nyh granulocitov v progressirovanii mekhanicheskoj zheltuhi v zavisimosti ot urovnya bilirubina i geneza zheltuhi [Chemiluminescent activity of neutrophilic granulocytes in the progression of obstructive jaundice, depending on the level of bilirubin and the genesis of jaundice]. Medicinskaya immunologiya [Medical Immunology]. 2016. T. 18. № 3. S. 269-278.

\section{ДАННЫЕ ОБ АВТОРАХ}

Москаленко Ольга Леонидовна, старший научный сотрудник, кандидат биологических наук

Федеральное государственное бюджетное научное учреждение «Научно-исследовательский институт медииинских проблем Севера»

ул. Партизана Железняка, 32, г. Красноярск, 660022, Российская Федерация gre-ll@mail.ru

Филимонова Людмила Анатольевна, доцент кафедры пропедевтики внутренних болезней и терапии, кандидат медицинских наук 
ГБОУ ВПО «КрасГМУ им. проф. Ф.В. Войно-Ясенеикого» МЗ РФ ул. Партизана Железняка, 1a, г. Красноярск, 660022, Российская Федерация selinala@mail.ru

Яскевич Роман Анатольевич, доцент кафедры пропедевтики внутренних болезней и терапии, вед. науч. сотрудник, кандидат медицинских наук ГБОУ ВПО «КрасГМУ им. проф. Ф.В. Войно-Ясенеикого» МЗ РФ; Федеральное государственное бюджетное научное учреждение «Научно-исследовательский институт медицинских проблем Севера» ул. Партизана Железняка, 1а, г. Красноярск, 660022, Российская Федерачия; ул. Партизана Железняка, 32, г. Красноярск, 660022, Российская Федераиия cardio@impn.ru

\section{DATA ABOUT THE AUTHORS}

Moskalenko Olga Leonidovna, Senior Researcher, Candidate of Biological Sciences Federal State Budgetary Scientific Institution «Scientific Research Institute of medical problems of the North»

3g, Partizan Zheleznyaka str., Krasnoyarsk, 660022, Russian Federation gre-ll@mail.ru

Filimonova Lyudmila Anatolevna, associate professor at department of propedeutics of internal diseases and therapy, candidate of medical science, docent Krasnoyarsk State Medical University named after Professor V.F. Voino-Yasenetzkiy

1a, P. Zheleznyaka St., Krasnoyarsk, 660022, Russian Federation selinala@mail.ru

Yaskevich Roman Anatolyevich, associate professor at department of propedeutics of internal diseases and therapy, leading researcher, candidate of medical science, docent

Krasnoyarsk State Medical University named after Professor V.F. Voino-Yasenetzkiy; Federal State Budgetary Scientific Institution «Scientific Research Institute of medical problems of the North»

1a, P. Zheleznyaka St., Krasnoyarsk, 660022, Russian Federation; $3 g$, Partizan Zheleznyaka str., Krasnoyarsk, 660022, Russian Federation cardio@impn.ru 